\title{
Capacity building at the Asia Pacific Journal of Management
}

\author{
Michael Carney ${ }^{1}$
}

Published online: 13 November 2015

(C) Springer Science+Business Media New York 2015

This is my final editorial as editor-in-chief of Asia Pacific Journal of Management, a position I have held since January 2013, and I would like to take the opportunity to reflect upon my association with the Journal. Prior to my appointment as editor-in-chief I previously served a 5-year term as a senior editor having been an editorial review board member for several years before that. However, my first association with the Journal was through an APJM special issue conference on the Asian Multinational Corporation organized by former APJM editor Kulwant Singh at the National University of Singapore in February 1997, just as the Asian financial crisis was breaking throughout the region. The conference resulted in the publication of a 1998 $A P J M$ special issue dedicated to what is now referred to as emerging economy multinationals and to my knowledge APJM was the first journal to identify the now much researched phenomena (e.g., Carney, 1998; Makino \& Beamish, 1998; Wan, 1998).

The Asian financial crisis brought the world's attention to the region's economic miracle but it also highlighted several sources of fragility in the governance and management of its leading corporations (Ahlstrom, Young, Ng, \& Chan, 2004; Carney, 1998). Academic research on Asian management phenomena accelerated over the next two decades but as the Asian Financial unfolded in 1997 there were few obvious venues for like-minded management scholars to come together to share their insights and findings. APJM played a key role in filling that gap with its core focus on management research around the region as a whole, in cooperation with the Asia Academy of Management, and its continuing tradition of special issue development workshops that bring scholars together on specific themes. Over the years I attended several APJM special issue conferences in Bangkok, Beijing, Brisbane, Copenhagen, Taiwan, Vancouver, and most recently in Hong Kong. The links to Asia Academy of Management with its biennial meetings along with the annual special issue workshops

Michael Carney

michael.carney@concordia.ca

1 Concordia University, Montréal, Québec H3G 1M8, Canada 
helps construct a concrete network of relationships that help bind the APJM community together. Indeed, establishing and maintaining these relationships will become increasingly vital as the number of scholars interested in Asian management issues continues to grow.

When I assumed the chief editorship APJM had experienced a sustained period of growth in its recognition due to the entrepreneurial leadership of four previous editors: Kulwant Singh, Andrew Delios (both National University of Singapore), Mike Peng (University of Texas at Dallas) and David Ahlstrom (The Chinese University of Hong Kong). Together they set a course to strengthen the quality of work published in the Journal and raise its international profile. The success of their efforts is reflected in recent journal quality rankings which convincingly show that APJM is now consolidating itself as a top-level international business journal. APJM has attained a 5-year SSCI impact factor of 3.0. In a 2013 re-evaluation of its Journal Quality of List rankings the Australian Business Deans Council upgraded APJM from a B to an A, that is, second on a five-rank scale where A* is the highest. Similarly, the UK-based Association of Business Schools upgraded APJM in its 2015 Academic Journal Guide from 2 to 3 (on a five point scale of 1 to $4^{*}$ ) in the category of international business in the 2015. Moreover, Google Scholar Metrics ranks APJM fifth among the top 20 international business journals.

As we consolidate our identity as a leading international business journal submissions to the Journal continue to grow. In 2010 the year of our first impact factor we received 450 submissions. The submissions headed higher in subsequent years. In 2014 APJM received over 800 submissions and at the midpoint of 2015 we are on a course to surpass even that high number. As such, the acceptance rate has fallen: we will publish approximately 40 papers in 2015 for an acceptance rate of $5 \%$, placing our submission counts and acceptance rates consistent with many of the best ranked journals in the management and IB areas. During my t3-year term I have made preliminary editorial decisions on more than 2000 submissions. Inevitably the surge in submissions has taxed our ability to review and process papers in a timely manner. The primary difficulty, common in most peer-reviewed journals, is securing constructive and high-quality reviews for the most promising papers. During my editorship I noticed that while the majority of our submissions originated in greater China and East Asia the small editorial review board was mostly located in North America, Europe, and Australia. To restore the balance between the origin of submissions and reviewers I sought to expand the membership of our editorial review board and took steps increase the number of review board members located in institutions in greater China and East Asia. I am pleased to say that during the course of this expansion the editorial review board increased from less than 20 to 115 active members and I would like to thank them collectively for their commitments and support of the journal.

So it is with a feeling of pride and accomplishment that I can introduce our next editor-in-Chief Jane Lu who will take over the editor-in-chief mandate in January 2016. Jane is the James Riady Chair Professor at the University of Melbourne and is an accomplished international business scholar. She has done pioneering work on the internationalization and performances of small to medium-sized enterprise (e.g., Lu \& Beamish, 2004) and has subsequently produced a steady stream of research in the 
profession's most highly regarded academic journals (Lu, 2002; Lu \& Ma, 2008; Xia, $\mathrm{Ma}, \mathrm{Lu}, \& \mathrm{Yiu}, 2014)$. Her recent work on organizational forms and multi-population dynamics identifies the continuing contested legitimacy of China's private enterprises $(\mathrm{Xu}, \mathrm{Lu}, \& \mathrm{Gu}, 2014)$ a subject that will attract growing attention from scholars interested in China's transition. Jane brings a wealth of experience to her role as editor. She has served as a senior editor at the of the Journal of World business, and is a longserving APJM senior editor. Jane is currently editing a series of special issues on business groups (Journal of World Business), dragon multinationals (APJM) and inequality (Business and Society) and is a member of the editorial review board to the Management Organization Review, Journal of Management Studies and Journal of Business Research in the former board member of the Academy of Management Journal. There is no doubt that APJM will be in very capable hands over the next 3 years.

\section{Looking forward}

Across the Asia-Pacific region a growing number of business schools are joining the ranks of the world's leading business schools. Most have adopted North American performance appraisal standards to evaluate their faculty members' research productivity. This trend is well-established and likely to continue as new schools are founded and existing ones expand. Accordingly, it is reasonable to expect that Asia focused management research will continue to grow and management scholars will seek out appropriate venues for their work. APJM stands to benefit from these developments and will need to continue to enhance its editorial structure and capacity to process a large volume of submissions it receives.

Having established APJM as a leading international business journal we are increasingly viewed as a major venue for publishing research not only on Asia, but also on emerging and transition economies (e.g., Ismail, Ford, Wu, \& Peng, 2013). The journal has also sought to remain at the forefront of research in developing the institutional view strategy (Sauerwald \& Peng, 2013; Young, Tsai, Wang, Liu, \& Ahlstrom, 2014), emerging economy multinational enterprises (Meyer \& Thaijongrak, 2013; Popli \& Sinha, 2014), comparative corporate governance (Ding, Sun, \& Au, 2014; Filatotchev, Jackson, \& Nakajima, 2013) and the board (Liu, Wang, Zhao, \& Ahlstrom, 2013; Van Essen, Van Oosterhout, \& Carney, 2012). In addition, APJM continues to publish extensive indigenous research on management in Asia (Ahlstrom, Chen, \& Yeh, 2010; Horak \& Klein, 2015; Leung, Chen, Zhou, \& Lim, 2014; Li, 2012), the strategies and behaviors of Asian family firms and business groups (Au, Chiang, Birtch, \& Ding, 2013; Yabushita, \& Suehiro, 2014), and the role of government-business relationships (Dou \& Li, 2013; Li, Chen, Liu, \& Peng, 2014) and state enterprises (Maheshwari \& Ahlstrom, 2004; Stan, Peng, \& Bruton, 2014). However it is important to emphasize that APJM is also a general management journal that welcomes and publishes research on meso and micro level phenomena. In the last 5 years we have accentuated our emphasis on micro level research publishing high quality studies in areas such as Asian leadership (Lam, Huang, \& Lau, 2012; Sun, Xu, \& Shang, 2014), abusive supervision (Wei \& Si, 2013; Zhang \& Liao, 2015), procedural justice (Lin, 2015; Lam, Loi, \& Leong, 2013), emotion in organizations (Cheng, Huang, Lee, \& Ren, 2012; Li, 
Ahlstrom, \& Ashkanasy, 2010; Li, Ashkanasy, \& Ahlstrom, 2014), leadership (Liden, 2012), and organizational identification (Liu, Lam, \& Loi, 2014; Ngo, Loi, Foley, Zheng, \& Zhang, 2013).

APJM was established on, and continues to uphold, a developmental mandate to encourage and support new authors, especially from the Asia-Pacific region. The majority of our contributors are writing in a second language for them, and for some, an acceptance from APJM is their first publication in an English-language peer-reviewed journal. So I would like to acknowledge a debt of gratitude to the APJM senior editorial team that breathes life into our developmental mandate and who give generously of their time to help authors, often from developing Asia, develop their work and strengthen its contribution to the literature. I was fortunate to inherit from the previous editor-in-chief a seasoned team of experienced senior editors. Amazingly, many have continued to serve throughout my tenure including Shyh-jer Chen (National Sun Yat-sen University), Fang Lee Cooke (Monash University), Xu Huang (Hong Kong Baptist University), Hicheon Kim (Korea University), Rico Lam (University of Macau), Simon Lam (University of Hong Kong), Seung-Hyun Lee (University of Texas at Dallas), Jane Lu (University of Melbourne), Anil Nair (Old Dominion University), Alfred Wong (Lingnan University), Daphne Yiu (The Chinese University of Hong Kong), Kevin Zhou (University of Hong Kong). To meet the growing submissions I introduced several new editors including Nikos Bozionelos (Audencia, France), Christine Chan (University of Hong Kong), Ajau Guar (Rutgers University) Peter Ping Li (Copenhagen Business School), Steven Lui (University of New South Wales), and John Matthews (Macquarie University). Naturally, there is some turnover among the membership of the editorial team as several had to step down from APJM and move on to new responsibilities recently including Yaping Gong (Hong Kong University of Science and Technology, China), Eric Gedajlovic (Simon Fraser University), Klaus Meyer (CEIBS), Peter Ping Li (Copenhagen business school) and Michael Young (Hong Kong Baptist University). On behalf of APJM and the community of scholars who are interested in its progress, I would like to say how very much we appreciate their service and commitment to the Journal.

On behalf of APJM I would also like to acknowledge the contributions of Rachel (Rae) Pinkham as managing editor, Janaki Ramesh and Jurgen Torres-Ventula of our publisher Springer and Linda Rice for their editorial and research assistance. For their financial support of APJM's activities thanks go out to Hasan Pirkul, Dean of the Naveen Jindal School of Management, at the University of Dallas Texas, Blaize Horner Reich, Dean of the Beedie School of business, Simon Fraser University, Vancouver and Steve Harvey, Dean of the John Molson school of business Montréal. Finally I would like to acknowledge the continuous support I have enjoyed from former editors in chief Mike Peng University of Texas Dallas and David Ahlstrom of The Chinese University of Hong Kong.

\section{The Mike Peng best paper award}

Finally, with this editorial, I am also pleased to announce the winners of the seventh best paper award at APJM (Table 1). The award winners receive a US \$1000 cash award kindly sponsored by our publisher, Springer. This year's Mike Peng best paper award winner is Victor Zitan Chen and his colleagues for their excellent study of the relationship between ownership structure and innovation in a large sample of publicly 
Table 1 The Mike Peng Best Paper Award for 2014

\author{
Announcing \\ The $7^{\text {th }}$ Annual Mike Peng Best Paper Award \\ Awarded to \\ Victor Zitan Chen, \\ Jing Li \\ Daniel M. Shapiro \\ Xiaoxiang Zhang
}

Ownership structure and innovation: An emerging market perspective

Asia-Pacific Journal of Management

Previous best paper award winners in the Asia Pacific Journal of Management

2013

Peter Ping $\mathrm{Li}$, "Toward an integrative framework of indigenous research:

The geocentric implications of Yin-Yang Balance” 2012, 29 (4): 849-872.

2012

Marc van Essen, J. Hans van Oosterhout, Michael Carney, 2012 (29 (4): 873-905)

Corporate boards and the performance of Asian firms: A meta-analysis

2011

Kenneth S. Law, Chi-Sun Wong, Guo-Hua Huang, Xiaoxuan Li, 2008 (25 (1): 51-69)

The effects of emotional intelligence on job performance and life satisfaction for the research and development scientists in China

2010

Mike W. Peng, 2005 (22 (2): 123-141)

From China strategy to global strategy

2009

John A. Mathews, 2006 (23 (1): 5-27)

Dragon multinationals: New players in 21 st century globalization

2008

Klaus E. Meyer, 2006 (23 (2): 119-137)

Asian management research needs more self-confidence

listed Chinese companies. The contribution of the paper is to draw attention to the importance of 'owner identity' diversity in explaining innovation performance in a literature that is dominated by ownership concentration explanations. The awards committee commented on the strong quality of the contribution and noted the healthy flow of citations the paper is generating. The committee also noted that the papers authors, consisting of Simon Fraser University faculty and former PhD students has done good work and been keen supporters of the Journal. With the enduring support of APJM's fine editorial board, reviewers, and authors, I expect that APJM will continue its growth as an important outlet for management research in the Asia-Pacific region.

\title{
References
}

Ahlstrom, D., Young, M. N., Ng, F., \& Chan, C. 2004. High technology and globalization challenges facing overseas Chinese entrepreneurs. SAM Advanced Management Journal, 69(2): 28-37. 
Ahlstrom, D., Chen, S. J., \& Yeh, K. S. 2010. Managing in ethnic Chinese communities: Culture, institutions, and context. Asia Pacific Journal of Management, 27(3): 341-354.

Au, K., Chiang, F. F., Birtch, T. A., \& Ding, Z. 2013. Incubating the next generation to venture: The case of a family business in Hong Kong. Asia Pacific Journal of Management, 30(3): 749-767.

Carney, M. 1998. A Management capacity constraint? Obstacles to the development of the overseas Chinese family business. Asia Pacific Journal of Management, 15(2): 137-162.

Cheng, T., Huang, G.-h., Lee, C., \& Ren, X. 2012. Longitudinal effects of job insecurity on employee outcomes: The moderating role of emotional intelligence and the leader-member exchange. Asia Pacific Journal of Management, 29(3): 709-728.

Ding, Z., Sun, S. L., \& Au, K. 2014. Angel investors' selection criteria: A comparative institutional perspective. Asia Pacific Journal of Management, 31(3): 705-731.

Dou, J., \& Li, S. 2013. The succession process in Chinese family firms: A guanxi perspective. Asia Pacific Journal of Management, 30(3): 893-917.

Filatotchev, I., Jackson, G., \& Nakajima, C. 2013. Corporate governance and national institutions: A review and emerging research agenda. Asia Pacific Journal of Management, 30(4): 965-986.

Horak, S., \& Klein, A. 2015. Persistence of informal social networks in East Asia: Evidence from South Korea. Asia Pacific Journal of Management, 1-22.

Ismail, K., Ford, D. L., Wu, Q., \& Peng, M. W. 2013. Managerial ties, strategic initiatives, and firm performance in Central Asia and the Caucasus. Asia Pacific Journal of Management, 30(2): 433-446.

Lam, L. W., Huang, X., \& Lau, D. C. 2012. Leadership research in Asia: Taking the road less traveled?. Asia Pacific Journal of Management, 29(2): 195-204.

Lam, L. W., Loi, R., \& Leong, C. 2013. Reliance and disclosure: How supervisory justice affects trust in supervisor and extra-role performance. Asia Pacific Journal of Management, 30(1): 231-249.

Leung, K., Chen, Z., Zhou, F., \& Lim, K. 2014. The role of relational orientation as measured by face and renqing in innovative behavior in China: An indigenous analysis. Asia Pacific Journal of Management, 31(1): 105-126.

Li, P. P. 2012. Toward an integrative framework of indigenous research: The geocentric implications of YinYang Balance. Asia Pacific Journal of Management, 29(4): 849-872.

Li, Y., Ahlstrom, D., \& Ashkanasy, N. M. 2010. A multilevel model of affect and organizational commitment. Asia Pacific Journal of Management, 27(2): 193-213.

Li, Y., Ashkanasy, N. M., \& Ahlstrom, D. 2014a. The rationality of emotions: A hybrid process model of decision-making under uncertainty. Asia Pacific Journal of Management, 31(1): 293-308.

Li, Y., Chen, H., Liu, Y., \& Peng, M. W. 2014b. Managerial ties, organizational learning, and opportunity capture: A social capital perspective. Asia Pacific Journal of Management, 31(1): 271-291.

Liden, R. C. 2012. Leadership research in Asia: A brief assessment and suggestions for the future. Asia Pacific Journal of Management, 29(2): 205-212.

Lin, X. 2015. How does procedural justice climate influence individual outcomes? An affective perspective. Asia Pacific Journal of Management, 32(3): 771-800.

Liu, Y., Wang, L. C., Zhao, L., \& Ahlstrom, D. 2013. Board turnover In Taiwan's public firms: An empirical study. Asia Pacific Journal of Management, 30(4): 1059-1086.

Liu, Y., Lam, L. W., \& Loi, R. 2014. Examining professionals' identification in the workplace: The roles of organizational prestige, work-unit prestige, and professional status. Asia Pacific Journal of Management, 31(3): 789-810.

Lu, J. W. 2002. Intra-and inter-organizational imitative behavior: Institutional influences on Japanese firms' entry mode choice. Journal of International Business Studies, 33(1): 19-37.

Lu, J. W., \& Beamish, P. W. 2004. International diversification and firm performance: The S-curve hypothesis. Academy of Management Journal, 47(4): 598-609.

Lu, J. W., \& Ma, X. 2008. The contingent value of local partners' business group affiliations. Academy of Management Journal, 51(2): 295-314.

Maheshwari, S. K., \& Ahlstrom, D. 2004. Turning around a state owned enterprise: The case of Scooters India limited. Asia Pacific Journal of Management, 21(1/2): 75-101.

Makino, S., \& Beamish, P. 1998. Local ownership restrictions, entry mode choice, and FDI performance: Japanese overseas subsidiaries in Asia. Asia Pacific Journal of Management, 15(2): 119-136.

Meyer, K. E., \& Thaijongrak, O. 2013. The dynamics of emerging economy MNEs: How the internationalization process model can guide future research. Asia Pacific Journal of Management, 30(4): 1125-1153.

Ngo, H.-y., Loi, R., Foley, S., Zheng, X., \& Zhang, L. 2013. Perceptions of organizational context and job attitudes: The mediating effect of organizational identification. Asia Pacific Journal of Management, 30(1): 149-168. 
Popli, M., \& Sinha, A. K. 2014. Determinants of early movers in cross-border merger and acquisition wave in an emerging market: A study of Indian firms. Asia Pacific Journal of Management, 31(4): 1075-1099.

Sauerwald, S., \& Peng, M. W. 2013. Informal institutions, shareholder coalitions, and principal-principal conflicts. Asia Pacific Journal of Management, 30(3): 853-870.

Stan, C., Peng, M. W., \& Bruton, G. D. 2014. Slack and the performance of state-owned enterprises. Asia Pacific Journal of Management, 31(2): 473-495.

Sun, W., Xu, A., \& Shang, Y. 2014. Transformational leadership, team climate, and team performance within the NPD team: Evidence from China. Asia Pacific Journal of Management, 31(1): 127-147.

Van Essen, M., Van Oosterhout, J. H., \& Carney, M. 2012. Corporate boards and the performance of Asian firms: A meta-analysis. Asia Pacific Journal of Management, 29(4): 873-905.

Wan, C. C. 1998. International diversification, industrial diversification and firm performance of Hong Kong MNCs. Asia Pacific Journal of Management, 15(2): 205-217.

Wei, F., \& Si, S. 2013. Tit for tat? Abusive supervision and counterproductive work behaviors: The moderating effects of locus of control and perceived mobility. Asia Pacific Journal of Management, 30(1): 281-296.

Xia, J., Ma, X., Lu, J. W., \& Yiu, D. W. 2014. Outward foreign direct investment by emerging market firms: A resource dependence logic. Strategic Management Journal, 35(9): 1343-1363.

$\mathrm{Xu}, \mathrm{D} ., \mathrm{Lu}, \mathrm{J}$. W., \& Gu, Q. 2014. Organizational forms and multi-population dynamics: Economic transition in China. Administrative Science Quarterly, 59(3): 517-547.

Yabushita, N. W., \& Suehiro, A. 2014. Family business groups in Thailand: Coping with management critical points. Asia Pacific Journal of Management, 31(4): 997-1018.

Young, M. N., Tsai, T., Wang, X., Liu, S., \& Ahlstrom, D. 2014. Strategy in emerging economies and the theory of the firm. Asia Pacific Journal of Management, 31(2): 331-354.

Zhang, Y., \& Liao, Z. (2015). Consequences of abusive supervision: A meta-analytic review. Asia Pacific Journal of Management, (this issue).

Michael Carney ( $\mathrm{PhD}$, University of Bradford) is the Concordia University Research Chair in Strategy and Entrepreneurship at the John Molson School of Business, Montréal and visiting professor at Renmin University China. He has published extensively on the corporate and organizational strategies of Asia's family-owned business groups. He is the outgoing editor-in-chief of the Asia Pacific Journal of Management. His research is published in Academy of Management Journal, Asia Pacific Journal of Management, Journal of Management, Journal of Management Studies, Management and Organization Review, Organizations Studies, and Strategic Management Journal. 